\title{
CMPA fees will go up - and down
}

U nder a new cost structure put in place by the Canadian Medical Protective Association (CMPA) fees for some physicians will increase substantially while others will experience a noticeable drop. The determining factor is geography.

At present, the nonprofit CMPA, which provides legal assistance to physicians and pays financial awards to successful plaintiffs, has three fee regions: Ontario, Quebec and the Rest of Canada. Beginning in 2016, a new fee region British Columbia and Alberta - will be created and the Rest of Canada region will comprise only Saskatchewan, Manitoba, Atlantic Canada and the territories.

"The main driver in this is the cost of protection," CMPA Executive Director and CEO Dr. Hartley Stern told the 200-plus attendees at the association's Aug. 27 annual meeting in Halifax.

Physicians in Ontario will be hardest hit by fee increases. The province has experienced a $29 \%$ increase in the aggregate fee requirement, an amount generated by actuarial models that follow industry best practices. This jump in provincial costs translates into an additional \$2225 per physician.

"In 2014, we entered into a deficit position, and are now working to get back to full funding over a five-year period," Stern said. The province's pecuniary position, he noted, is the result of two factors: rising protection

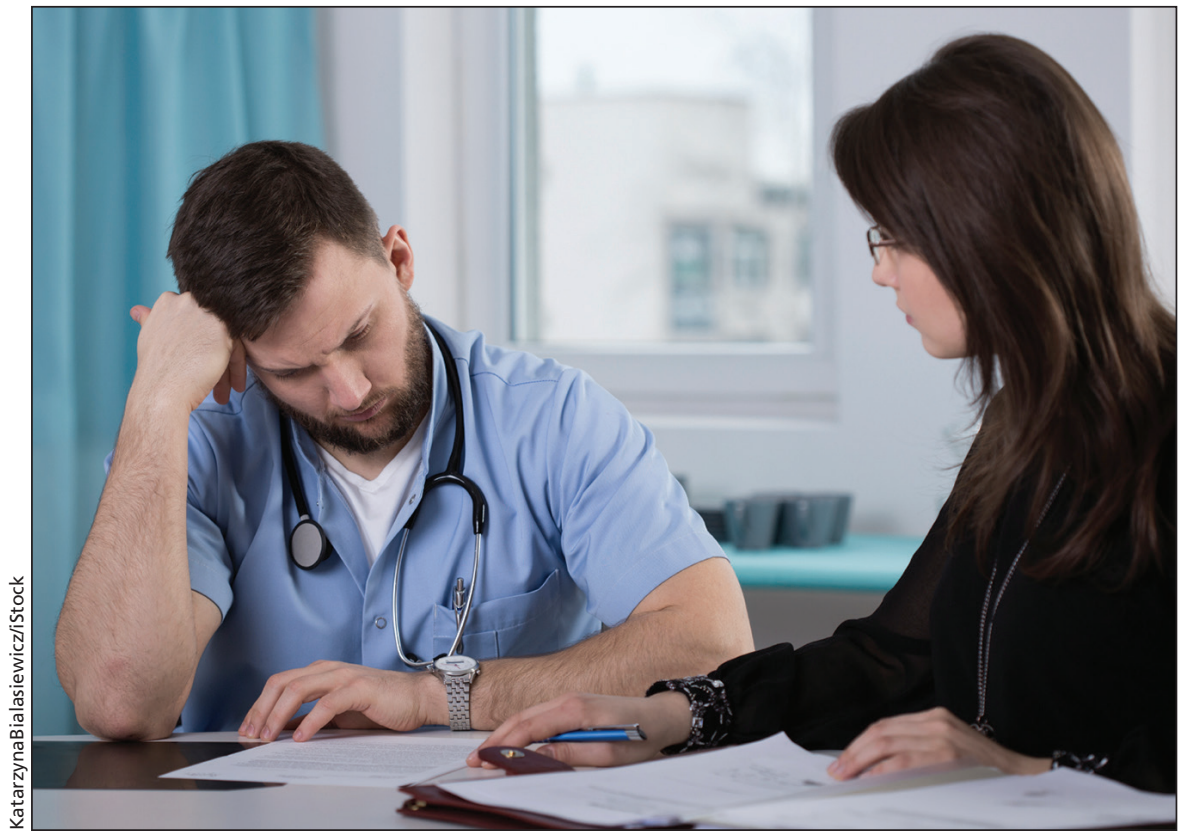

Physicians' fees for legal assistance will vary depending upon where they live.

compensating injured patients in the new region, will translate into a $6.5 \%$ hike in fees or $\$ 387$ more per member, Stern said.

The Quebec region has experienced relatively stable costs and as a result no fee increase is slated for 2016. The aggregate fee requirement is $\$ 81$ million, roughly the same as it has been for the last two years. "The trend shows a fairly modest increase and we have chosen to maintain the cost per member," Stern said.

\section{Physicians in Ontario will be hardest hit with a fee increase of $29 \%$.}

costs and a previous Ontario government decision to divert more than $\$ 250$ million earmarked for CMPA to offset another funding obligation.

In the British Columbia and Alberta region, the aggregate fee requirement for 2016 is $\$ 156$ million, which is about $10 \%$ higher than in 2015. This increase, which reflects the increased costs of
Physicians in the Rest of Canada will see their fees drop next year. In Saskatchewan, Manitoba, the Atlantic provinces, and territories, where protection costs are lower, the aggregate fee requirement for 2016 is $\$ 46$ million, a decline of $40 \%$. For individual doctors, this means an average savings of $\$ 2388$.

The association's new regional struc- ture is necessary to offset emerging differences in protection costs, particularly in the Rest of Canada region over the last two years, CMPA President Dr. Edward Crosby told attendees. "This divergent experience, if not addressed, would undermine the association's commitment to member equity in its fees."

Stern reassured members that under the existing system there has been an equal paying field. "No region has been disadvantaged," he stressed. "There has been no subsidization of one region for another."

The 2016 membership fee schedule is now available; physicians will be able to access their 2016 fee invoices online in late October. - donalee Moulton, Halifax, NS

CMAJ 2015. DOI:10.1503/cmaj.109-5149

\section{More News online}

To read more CMAJ news articles, visit cmaj.ca/site/home/news.xhtml 